Bol. Acad. peru. leng. 49. 2010 (99-113)

\title{
VARIACIONES LÉXICAS DE LAS FRASES Y LOCUCIONES
}

\author{
VARIATION LEXICALE DES PHRASES ET DES PHRASES
}

\section{LEXICAL VARIATION OF SENTENCES AND PHRASES}

\author{
Consuelo Meza Lagos \\ Sociedad Peruana de Estudios Léxicos (Spelex)
}

\begin{abstract}
Resumen:
Las palabras varían a través del tiempo y por qué no frases, refranes y locuciones las cuales han sufrido variantes en su significante. El proceso probable que han seguido en el camino es de amalgamar términos relacionando palabras diferentes, pues el hablante hace asociaciones mentales subjetivas que aproximan -ya por el sonido ya por el significadoa la frase en sí misma, con una sola intención: la de dar expresividad con formas nuevas desarrolladas a partir de estas frases o lexías conocidas, recalcar o apoyar una argumentación acorde con su época, con su vivencia cotidiana ¿Qué ocurrió, por ejemplo, con no ato ni trasquilo, que estaba vigente en la primera mitad del siglo XX, en comparación con no ato ni desato? Explorar el posible proceso, mostrar y explicar algo de la evolución de estas expresiones es propósito del presente trabajo.
\end{abstract}

Résumé:

Les mots varient dans le temps et pourquoi pas des phrases, des proverbes et des locutions lesquelles ont souffert des variations de sa signification. Le processus qui ont suivi sur la route c'est de continuer à relier, pour 
fusionner les termes des différents mots, comme l'orateur fait des associations mentales subjectives qui s'approchent soit par le son ou le sens de l'expression telle qu'elle est, avec une seule intention: donner une expression à de nouvelles formes développés à partir de ces expressions familières ou lexías déjà connues, mettre l'accent ou appuyer un argument en ligne avec le temps, avec leur vie quotidienne, Qu'est-il arrivé, avec no ato ni trasquilo par exemple, qui était en vigueur dans la première moitié du XXe siècle, comparativement à no ato ni desato? Découvrir le processus possible, montrer et expliquer un peu de l'évolution de ces expressions est le but de cet article.

\section{Abstract:}

The words vary over time and why not phrases, sayings and phrases which have been variations in its significance. The process likely to have continued on the road linking it to amalgamate different word terms, as the speaker makes subjective mental associations that approach-and by the sound and the meaning to the phrase "in itself, with one intention: to give expression to new forms developed from these familiar phrases or ley, stress or support an argument in line with the times, with their daily lives What happened, for example, with no tie or shearing, which was in force in the first half of twentieth century, compared with no tie or untie? Explore the possible process, show and tell something of the evolution of these expressions is the purpose of this paper.

Palabras clave:

Cambio léxico; frases; locuciones.

Mots clés:

Changement lexical; phrases; locutions.

Key words:

Lexical change; phrases; expressions.

Fecha de recepción:

$23 / 03 / 2008$

Fecha de aceptación: $02 / 01 / 2010$ 
Las frases o locuciones han seguido muchas veces mecanismos de cambio muy peculiares que nos llevan a reflexionar acerca de los posibles caminos seguidos en su evolución. Pese a que sintácticamente tienen una fijación formal, pueden presentar una forma relativa y muy variada. Así, por ejemplo, algunas se mantienen invariables pese al tiempo, como nunca faltó un roto para un descosido, un clavo saca a otro clavo, debido a que existen unidades fraseológicas de fijación absoluta, porque no permiten cambios estructurales y el significado figurado no varía. Otras, por el contrario, pueden resultar flexibles, pues admiten sustituciones o inserciones que generan frases nuevas en la forma como, por ejemplo, lo dicho por aquel vilipendiado funcionario electoral peruano que en un exabrupto afirmó papelito manda, y no papelito habla, expresión registrada ya en el DRAE y usada por Ricardo Palma en sus Tradiciones. ${ }^{1}$ Por último, existen las llamadas frases de fijación intermedia que permiten modificaciones predeterminadas, por ejemplo echar/arrojar algo por la ventana, quitarse/sacarse el sombrero (Belichón, 1999). ${ }^{2}$

Las frases o locuciones cumplen una finalidad que es la de dar mayor expresividad a lo que se argumenta. Las unidades fraseológicas llamadas frases hechas que describen un hecho sin llegar a transmitir un mensaje o moraleja (nivel denotativo), semánticamente destacarán por su idiomaticidad, concepto propuesto por Corpas Pastor en su libro Manual de Fraseología Española, en el cual explica que el "significado global de dicha unidad no es deducible del significado aislado de cada uno de los elementos constitutivos". ${ }^{3}$ De acuerdo a este concepto, las unidades fraseológicas pueden ser menos idiomatizados o transparentes como ir a la deriva, perder el tiempo, dormir el vino; otras, por el contrario, pueden ser más idiomatizadas como no ato ni trasquilo, sacar los trapos a la colada,

1 Ricardo Palma: "Carta canta" en Tradiciones Peruanas, Madrid, 1953, Ediciones Aguilar, p. 147.

2 Esta clasificación pertenece a Mercedes Belichón: "Psicolingüística del español" en Lenguaje no literal y aspectos pragmáticos de la comprensión, Madrid, 1999, M. de Vega y F. Cuetos ediciones, pp. 307-373.

3 http://www.scielo.cl/scielo.php?pid=S0718-48832006000200006\& script $=$ sci arttext[21-03-2008]. 
la flor y nata, pues no se puede acceder a su significado a través de sus componentes. Esta noción de idiomaticidad remite a algo propio del idioma, lo cual nos lleva a pensar que también pueden ser dialectales, pues una variante puede pertenecer exclusivamente a un país determinado.

Las unidades fraseológicas se dividen en aquellas que son actos de habla completos y aquellas que no lo son. Las locuciones estarían en este segundo grupo, pues son unidades fraseológicas que no contienen enunciados completos.

El proceso de cambio no solo ocurre por razones lingüísticas, sino también obedece a factores sociales, acordes con las vivencias de la época, además de asociaciones mentales de carácter subjetivo. Es de esperar que el cambio ocurra en el significado cuando cambia el significante, aun cuando se tenga el mismo referente; sin embargo, puede pasar que un cambio de significante no afecte al significado general. Es decir, en estas frases o locuciones flexibles en las que cambia algún componente, el hablante opera conservando el sentido general de la frase o locución, de manera que la palabra nueva -esto es, la que reemplaza a alguna de la secuencia original- ocupa el lugar de la otra sin que exista variación alguna en el sentido de la frase o locución. En este proceso se produce una neutralización del significado de las palabras conmutadas, como veremos en los ejemplos.

La motivación para el cambio es variada; puede ser por razones sociales acordes con las vivencias del hablante, o por factores psicológicos que expresan su deseo de reforzar el significado, pues el mensaje sigue siendo el mismo. También puede responder a aspectos formales de la lengua (procesos de similicadencia, pleonasmo, entre otros). Así tenemos: no ato ni trasquilo > no ato ni desato; la flor y nata > la crema y nata; sacar los trapos a la colada > sacar los trapos al aire; dormir el vino > dormir la mona, entre otras. 


\section{No ato ni trasquilo}

En: "La verdad quede en su sitio, que yo ni ato ni trasquilo, y no estoy de humor para discurrir sobre si fueron verdes o fueron maduras", ${ }^{4}$ la frase utilizada es no ato ni trasquilo, equivalente al contemporáneo no ato ni desato. Según el DRAE no ato ni desato es una locución verbal coloquial con dos acepciones: "1. Hablar sin concierto. 2. No resolver ni determinar nada en ningún sentido". Cobarruvias en su diccionario Tesoro de la Lengua Castellana o Española ${ }^{5}$ registra ni ata ni desata, mas no no ato ni desato, tal vez porque la primera era muy común y la segunda no. Ni ata ni desata tenía la siguiente definición: "Del que no dize cosa concertada". Esto demuestra que con el correr del tiempo se fue extendiendo a una nueva acepción, pues el diccionario académico de 1884 ofrece dos acepciones: "fr. fig. fam. Hablar sin concierto $\|$ fig. fam. No resolver ni determinar nada en ningún sentido”. Pero ¿qué sucedió con no ato ni trasquilo? Se fue quedando en el tintero, pese a que en el CORDE existen solo en narrativa más de 1446 casos registrados, y en todos los documentos se cuenta 30957 en total. Cosa curiosa es que en el CORDE no se muestran casos de ni ata ni desata (que Cobarruvias sí consideró), pero sí de no ato ni desato. Contrariamente, el CORDE registra no ato ni trasquilo en su documentación de casos, pero nunca fue considerada por la Academia sinónimo de no ato ni desato.

En el diccionario académico de 1780 se registra ni ata ni desata de la siguiente manera: "f. Que se dice del que habla sin concierto ó no sabe dar razon de lo que está á su cargo", lo cual nos lleva a suponer que se siguió el siguiente camino: ni ato ni desato $>$ no ato ni trasquilo $>$ no ato ni desato.

No ato ni trasquilo se decía vigorosamente en los albores del XIX, tal como vemos en las Tradiciones de Palma, o como lo registra el CORDE en el Perú en el año 1939 en un texto periodístico. ${ }^{6}$ También en países como

$4 \quad$ Ricardo Palma: "Don Alonso el Membrudo", ob. cit. 71.

5 Sebastián de Cobarruvias Orozco: Tesoro de la Lengua Castellana o Española, Madrid, 1984, Ediciones Turner, p. 163.

6 Real Academia Española: Banco de datos (CORDE) [http://corpus.rae.es/cgi-bin/ crpsrvEx.dll]. Corpus diacrónico del español. <http://www.rae.es> [03-03-2008] 
la Argentina y Bolivia, desde aproximadamente 1927, y en Chile existen registros desde el año 1548. En dicha exploración, la frase aparece registrada muy profusamente; sin embargo, haciendo un recorrido por los diccionarios de la Academia, ninguno la ha registrado. ¿Qué llevó al hablante a utilizar desata por trasquilo? En el diccionario académico de 1780, trasquilar se definía así en una de sus acepciones: "met. Menoscabar, ó disminuir alguna cosa, quitando, ó separando parte de ella". El hablante pudo hacer asociación del significado por separado de ambas palabras, en un esfuerzo semántico: en no ato ni trasquilo debió reparar en que los significados de atar y trasquilar, aun cuando estuvieran asociados en la frase, no eran necesariamente cercanos; entendió que el sentido o mensaje era 'no uno algo, ni separo algo'; de aquí a pensar que era cómodo semántica y fonéticamente relacionar atar y desatar, opuestos y complementarios, había poco trecho. Así, en el caso de las locuciones bimembres no ato ni desato por no ato ni trasquilo -en las que el primer miembro está encabezado por no y el segundo por ni-, el hablante opta por usar la misma raíz verbal en ambas miembros de la frase, encuentra una coincidencia en los sonidos, aplica la similicadencia y así llega a ato y desato. Esto, por supuesto, sin que cambiase el significado de la locución.

\section{La flor y nata}

"así como la reputación de esforzados y mañeros que disfrutaban, por hallarse entre ellos muchos hombres de gran experiencia en cosas de guerra y milicia, como que eran la flor y nata de los conquistadores que con Pizarro vinieron al Perú”.?

Desde 1732, se define el término flor así: "metafóricamente significa la parte más escogida y selecta de una cosa", pero también, en otra de sus acepciones se lee: "la nata que hace el vino en lo alto de la cuba. Flos" (DRAE 1817), mientras que a nata en su tercera acepción (DRAE 22 edición) se la define como: "Cosa principal y más estimada en cualquier

7 Ricardo Palma: "El caballo de Santiago apóstol", ob. cit. p. 71. 
línea". Las dos palabras independientemente nos llevan a conceptualizar "lo selecto de algo". Unidas en una frase, denotan que son "lo más selecto y estimado de algo". En el Perú, como en otros países en que se habla nuestra lengua, surge una variante: la voz flor es reemplazada por crema; entonces se ha dado lugar a la crema y nata, tal como encontramos en la siguiente cala: "Pésimas noticias había, en cambio, para los mellizos Arturo y Raúl. Porque, oh, horror, las más pobres de todas las descendientas pobres del pobre héroe, resulta que llevaban un segundo apellido de esos que en Lima de los cincuenta sonaban a mucho más que a la crema y nata". ${ }^{8}$

Explorando el CREA, de Ecuador encontramos la siguiente cita: "Cristina e Iñaki se convirtieron en marido y mujer en una ceremonia oficiada por el arzobispo de Barcelona Ricard María Carles, y en la que estuvieron reunidos por primera vez desde la muerte de la princesa Diana de Gales, la crema y nata de la realeza europea".

Tanto en Ecuador, la Argentina como en Guatemala, se ha dado pase a la crema y nata; en España, todavía se encuentra muy extendido el uso de flor y nata, pero existen evidencias de que también el cambio se ha manifestado reemplazando flor por crema, como por ejemplo en el diario El Mundo, de fecha 19-02-1994, se publicó lo siguiente: "Edith Newbold Jones nació en Nueva York el 24 de enero de 1862, en el seno de una familia que pertenecía a la crema y nata de la sociedad neoyorquina". ${ }^{10}$ Aunque se puede pensar que el periodista es un corresponsal extranjero, encontramos otros ejemplos que evidencian el uso de crema y nata en obras como la del novelista y miembro de la Real Academia Española Torcuato Luca de Tena: "Se trataba con los "Magníficos"; conversaba con los superiores; se paseaba del brazo con las dos mujeres que eran la

$8 \quad$ Alfredo Bryce Echenique: El huerto de mi amada, Barcelona, 2002, Planeta, p. 197.

9 Real Academia Española: Banco de datos (CREA) [http://corpus.rae.es/cgi-bincrpsrvEx. dll]. Corpus de referencia del español actual. <http://www.rae.es> [22-02-2008]

10 Real Academia Española: Banco de datos (CREA) [http://corpus.rae.es/cgi-bin/ crpsrvEx.dll]. Corpus de referencia del español actual. <http://www.rae.es> [22-0220008] 
crema y nata del manicomio". ${ }^{11}$ Ahora bien, ¿qué pudo haber influido en el hablante para preferir crema y nata y no flor y nata? Esta superposición de términos - de flor por crema- puede haber tomado el siguiente camino: Por un lado, el hablante común y corriente habrá reflexionado sobre el significado de flor, pues en países como el nuestro, el significado de flor para designar lo selecto ha perdido su vigencia. Flor es considerada básicamente parte de una planta, y por cierto, una bella parte de la planta; entonces, no encontró una relación lógica semántica que justificara tal relación entre los dos términos -que en realidad constituyen una sola palabra-; en cambio, crema contiene el concepto de "nata de la leche" y nata el concepto de "aquella crema blanca o amarillenta que se forma sobre la leche que está en reposo'; ambos comparten el mismo referente "lácteo" y, por tanto, se relacionan mejor, con lo cual el hablante, al realizar el cambio, respetó el género femenino de la construcción, y complementó y reforzó la idea de nata al cambiar flor por crema. Así, crema y nata resultan complementarios semánticamente. Luego, la crema y nata se definirá sinónimo de la flor y nata: "f. flor ( $\|$ lo más escogido de algo). La flor y nata de la sociedad." (DRAE 22. a edición).

Si nos remontamos a épocas pasadas, este otro ejemplo de Juan Valera, del año 1897, nos ilustra cómo iba tomando sus matices esta frase: "Con tales aprestos, don Joaquín, mejorado de facha, empezó a ganar amigos, y Rafaela, bien vestida, mejor hablada, decorosa e insinuante, fue haciendo olvidar su vida pasada, se introdujo poco a poco entre la flor y la crema de la sociedad". ${ }^{12}$ Más aún, encontramos este otro ejemplo de Lucio Vicente López (Argentina) en su publicación del año 1884: "como el profeta de Münster tenía una especie de virtud inconsciente e involuntaria para revolver las cabezas femeninas, y a pesar de toda su gravedad, de todo su juicio, contábase como cierto por los adversarios, que más de una vez, la crema de la high-life del tiempo, las señoras más encopetadas de Buenos Aires, le habían hecho manifestaciones públicas

\footnotetext{
11 Torcuato Luca de Tena: Los renglones torcidos de Dios, Barcelona, 1979, Planeta, p. 313.

12 Juan Valera: Genio y Figura. Madrid, 1986, Cyrus De Coster, Cátedra, p. 85.
} 
de simpatía en las ventanas de su casa" ${ }^{13}$ El idioma francés también pudo servir de préstamo en el proceso, pues muy en boga estaba la frase la crème de la crème. Aquí se ofrece un registro de este hecho, extraído de Carlos Fuentes, cuya obra data de el año de 1958: "Pichi metió su cabecita de poodle en la nuca de Junior: - ¡Qué excitante, Junior! ¡Conocer tantos intelectuales! La crema de la crema, como quien dice" ${ }^{14}$ En suma, la frase flor y nata tomó diferentes matices tales como la crema, la flor y la crema, la crema de la crema, crema y nata, mas el significado de la frase no cambió.

\section{Sacar los trapillos a la colada}

"Y en corroboración de estas mis palabras, no tengo más que sacarle los trapillos a la colada a cierta Beatriz, viuda de Perico Bustinza, que no a humo de pajas escribió aquello de:

de las carnes el carnero, de los pescados el mero". 15

Colada es según el DRAE (22.a edición): "1. f. Acción y efecto de colar. \|2. f. Lejía en que se cuela la ropa. \| 3. f. Ropa colada. \|4. f. Lavado de ropa sucia de una casa. $\| 5$. f. Ropa lavada”.

Cobarruvias nos explica el significado de colada del siguiente modo: "La lexía que se haze para limpiar los paños de lienço. Díxose assí porque se componen dentro de un vaso agujerado o de una canasta de mimbres, por donde la lexía, que es el agua que ha hervido con ceniza, se cuela y lleva tras sí todo lo suzio de los trapos [...] De dos espadas que tenía el Cid Rui Diaz, la una tuvo por nombre Colada, porque se devió forjar de finíssimo azero colado [...]". Nos queda claro que sacar los trapillos a la colada quiere expresar de manera figurada exponer lo sucio de algo. La Real

\footnotetext{
13 Lucio Vicente López: La gran aldea. Alicante, 2003, Universidad de Alicante, p. 33-34.

14 Carlos Fuentes: La región más transparente. México D. F., 1968, Fondo de Cultura económica, p. 18.

15 Ricardo Palma: "Quizá quiero, quizá no quiero", ob. cit. p. 37.
} 
Academia, a lo largo de las publicaciones de los diccionarios académicos, nunca consideró esta locución; pese a que en el CORDE encontramos registros de su evidente vigencia en pasadas épocas, que refuerzan la versión, líneas arriba, de Ricardo Palma. Así, por ejemplo, encontramos la cita de Benito Pérez Galdós en su obra Napoleón en Chamartín, publicado en el año 1874: "No pierde ripio para decir a todos las verdades, y a los españoles les suele sacar los trapitos a la colada, como quien dice". ${ }^{16}$

La colada como término pasó a ser en el Perú desusado. Esto no sucedió para los españoles, quienes hasta el día de hoy usan la frase hacer la colada para referirse al lavado de la ropa. Sin embargo, la locución sacar los trapillos a la colada dejó de ser tal, varió su composición original con los cambios colada por aire y trapillos por trapitos. En el Perú es notorio el uso del morfema diminutivo en trapo en esta forma: trapitos que no significa ser males menores, sino que denota una significación despectiva de carácter irónico. ${ }^{17}$ Por tanto, la locución pasó a ser sacar los trapos (trapitos) al aire, por cuanto el hablante quiere reforzar el significado de 'ventilar públicamente asuntos vergonzosos o reservados que se mantienen ocultos del conocimiento de otras personas'.

Semánticamente, en la frase que nos ocupa el verbo sacar se relaciona con el sustantivo aire, y sus semas son los de extraer, ventilar o poner algo afuera; para el caso de sacar, y el estar expuesto algo al aire, se estaría redundando en los semas del verbo. Esta forma redundante del hablante, llamada comúnmente pleonasmo, la encontramos en emisiones como subir arriba, bajar abajo, salir afuera, que son la misma forma redundante que sacar al aire; sin embargo, en este caso esta redundancia serviría de reforzamiento de la idea que se quiere expresar.

En España, por ejemplo, ya no se usa sacar los trapitos a la colada, pero sí sacar los trapos sucios. En el Perú coexisten estas dos formas: sacar los trapitos al

16 Real Academia Española: Banco de datos (CORDE) [http://corpus.rae.es/cgi-bin/ crpsrvEx.dl]. Corpus diacrónico del español. <http://www.rae.es> [03-03-2007]

17 Existen muchos casos en el castellano peruano del uso del morfema diminutivo -it con significación despectiva o irónica. Por ejemplo: es tu hijito preferido cuando el hijo es un hombre adulto, sin necesidad de ser necesariamente una persona de corta edad. 
aire o sacar los trapitos sucios (y el relacionado los trapos sucios se lavan en casa). Un trapo es un pedazo de tela desechado, y figuradamente significaría algo despreciable, humillante. En una de sus acepciones, sucio - calificativo del sustantivo trapito- es definido por el DRAE como 'Deshonesto u obsceno en acciones o palabras'. Como se ve, ambos términos (trapos y sucios) a la vez que guardan una relación de concordancia de sustantivo-adjetivo, mantienen una relación semántica figurada. Morfológicamente, sucio actuaría como intensificador del significado del sustantivo, de modo que trapo sucio llegaría a significar 'Algo muy despreciable o muy humillante'; ${ }^{18}$ al formarse la locución sacar los trapos sucios, trapos y sucios reforzarían el significado de la locución que fue el punto de partida (sacar los trapillos a la colada) a través de los semas despreciable, deshonesto, humillante. Así, sacar los trapillos a la colada > sacar los trapitos al aire sacar los trapos sucios, conservan su clasificación gramatical, además de su significado: "locs. verbs. coloqs. Echar a alguien en cara sus faltas y hacerlas públicas, en especial cuando se riñe con él acaloradamente" (DRAE 22. a edición).

\section{Dormir el vino}

"Pues habiendo en Arequipa convidado a comer a varios de sus amigos, éstos se excedieron en la bebida y al verlos caídos bajo la mesa exclamó doña Catalina: -¡Guay del Perú! ¡Y cuál están los que lo gobiernan! Mas Carbajal atajó la murmuración de su querida diciéndole con aspereza: -Cállate, vieja ruin, y déjalos dormir el vino por un par de horitas". ${ }^{19}$

Después del jolgorio y las bebidas, solo queda dormir el vino: "loc. verb. Dormir mientras dura la borrachera" (DRAE 22.a edición). Cobarruvias hace una extensa explicación histórica de la vid, cuando explica el lema vino, y su presencia desde que Dios crea al hombre; incluye la historia

\footnotetext{
18 De allí debe haberse generado lavar los trapos sucios, locución que significa 'Arreglar privadamente los aspectos enojosos de la vida personal'.

19 Ricardo Palma:"Si te dieren hogaza, no pidas torta" ob. cit. p. 85.
} 
de Baccho o Baco, dios del vino de los romanos, ${ }^{20}$ pero dormir el vino es una locución de la que no se ocupa ni la considera. Entonces ¿qué hizo pensar al hablante sobre el cambio del significante de vino a mona? Aquí Cobarruvias nos ilustra cuando leemos el significado de mona: "El Brocense, mona a verbo graeco ab imitando. Estas monas apetecen el vino y las sopas mojadas en él, y haze diferentes efetos la borrachez en ellas, porque unas dan en alegrarse mucho y dar muchos saltos [...]. De aquí vino llamar mona triste al hombre borracho que está melancólico y callado, y mona alegre al que canta y baila y se huelga con todos". ${ }^{21}$ En el diccionario académico de 1734, ya se leía el significado del lema mona: "En estilo jocoso y familiar se llama la embriaguéz o borrachera. Y también se llama así al que padece o está borracho”. Entonces, si la mona desde tiempos pasados es sinónimo de embriaguez, bien se justifica que en el Perú se diga que se pegó alguien la mona; es decir, se embriagó hasta transtornarse los sentidos - para imitar a la mona referida por Cobarruvias - y por ello el aludido necesita descansar. La locución dormir el vino resultó para el hablante con un rasgo semántico de [NO FESTIVO]. Para realizar el cambio, el hablante tuvo en cuenta los siguientes criterios: vino( en relación con dormir) tiene el rasgo [NO FESTIVO] y [NO ANIMADO]; el término reemplazante mona contiene el rasgo [FESTIVO] (habida cuenta de las gracias y acrobacias que ejecutan este animal), que se opone al [NO FESTIVO] de vino y también contiene el rasgo [ANIMADO] en oposición al [NO ANIMADO] de vino; además, mona debe relacionarse semánticamente con el significado concreto de la locución dormir el vino; de tal modo que siempre signifique: "Dormir hasta que se le pase la borrachera" (DRAE 1989). Y si la mona en su significación antigua representaba a la embriaguez (por los curiosos efectos que el licor producía en estos animales, como ya se mencionó), el significado no cambió, sino que se vio a salvo precisamente porque el significado de embriaguez se encontraba contenido en mona. De este modo, el rasgo [FEsTivo] de dormir la mona nació en oposición al rasgo [NO FESTIVO] de dormir el vino. Hoy en día es lo mismo decir que duerme el vino o duerme la mona, locución esta última que es común tanto en el Perú como en La Argentina, Bolivia, México,

$20 \quad$ Sebastián de Cobarruvias Orozco: ob. cit. p. 1009.

21 Sebastián de Cobarruvias Orozco: ob. cit. p. 810. 
Cuba y España, ${ }^{22}$ y que se registraba en el DRAE hasta 1989, pero que curiosamente ya no aparece en su edición actual.

\section{Conclusiones}

1. Cuando aparece una variante de una frase o locución de las analizadas, se observa que el elemento modificado (una palabra) de la nueva versión no altera el significado o mensaje de la frase o locución original.

2. En la variante de la frase o locución, el significado de la palabra modificada o nueva neutraliza su significado, acomodándose al molde semántico de la expresión original (neutralización semántica).

3. Existe una coexistencia diatópica de la frase o locución, de tal modo que tanto la variante como la original son usadas en territorios diferentes. Ambos casos mantienen el contenido semántico en el nivel de sintagma. Esto constituye una estabilidad semántica del mensaje que se sobrepone al cambio de los componentes de la frase o locución.

\section{BIBLIOGRAFÍA}

BELICHÓN, Mercedes. "Psicolingüística del español", Lenguaje no literal y aspectos pragmáticos de la comprensión, Madrid, M. de Vega y F. Cuetos ediciones, pp. 307-373. 1999

BLANCO, Desiderio y Raúl Bueno. Metodología del análisis semiótico, Lima, Editorial Universo. 1983

22 Real Academia Española: Banco de datos (CREA) [http://corpus.rae.es/cgi-bin/ crpsrvEx.d1l]. Corpus de referencia del español actual. <http://www.rae.es> [29-02-2008]

Bol. Acad. peru. leng. 49(49), 2010 
BRYCE ECHENIQUE, Alfredo. El huerto de mi amada, Barcelona, Planeta. 2002

CHAMIZO DOMÍNGUEZ, M. La metáfora (Semántica y pragmática). Extraído el 12 de marzo 2008 de: http://ensayistas.org/ critica/retorica/chamizo/cap 3.htm. 2005

COBARRUVIAS OROZCO, Sebastián. Tesoro de la Lengua Castellana o Española, Madrid, Ediciones Turner. 1984

CRESPO, Nina y Pablo Cáceres: La comprensión oral de las frases hechas: un fenómeno de desarrollo tardío del lenguaje. Extraído el 21 de marzo de 2008 de: http://www.scielo.cl/scielo. php?pid=S0718-48832006000200006\&script=sci_arttext

ECO, Humberto. La estructura ausente, Barcelona, Lumen. 1972

FUENTES, Carlos. La región más transparente, México D. F., Fondo de Cultura Económica. 1968

GREIMAS, A. Semántica Estructural, Madrid, Gredos. 1971

LÓPEZ, Lucio Vicente. La gran aldea. Alicante, Universidad de Alicante. 2003

LUCA DE TENA, Torcuato. Los renglones torcidos de Dios, Barcelona, Planeta. 1979

PALMA, Ricardo. Tradiciones Peruanas. Madrid, Ediciones Aguilar. 1953

RAE. Diccionario de la Lengua Española. Vigésima segunda edición. Consultado el 22 de febrero de 2008 en http://buscon. rae.es/drael/. 2008

Diccionario Academia Usual. Consultado el 03 de marzo de 2008 en http://buscon.rae.es/ntlle/SrvltGUIMenuNtl le? $\mathrm{cmd}=$ Lema\&sec $=1 \cdot 0 \cdot 0 \cdot 0 \cdot 0 \cdot 1884$ 
. Diccionario Academia Usual. Consultado el 22 de febrero de 2008 en http://buscon.rae.es/ntlle/SrvltGUIMenuNtl le? $\mathrm{cmd}=$ Lema\&sec $=1.0 .0 .0 .0 .1817$

- Diccionario Academia Usual. Consultado el 22 de febrero de 2008 en http://buscon.rae.es/ntlle/SrvltGUIMenuNtl le? $\mathrm{cmd}=$ Lema\&sec $=1 \cdot 0 \cdot 0 \cdot 0 \cdot 0 \cdot 1734$

. Diccionario Academia Usual. Consultado el 11 de febrero de 2008 en http://buscon.rae.es/ntlle/SrvltGUIMenuNtl le? $\mathrm{cmd}=$ Lema\&sec $=1 \cdot 0 \cdot 0 \cdot 0 \cdot 0.1732$

REAL ACADEMIA ESPAÑOLA: Banco de datos (CORDE).

REAL ACADEMIA ESPAÑOLA: Banco de datos (CREA).

RUIZ GURILLO, L. Las locuciones en el español actual, Madrid, Arco libros. 2001

SAUSSURE, Ferdinand. Curso de lingüistica general, Madrid, Alianza Editorial. 1983

VALERA, Juan. Genio y Figura. Madrid, Cyrus De Coster, Cátedra. 1986

\section{Correspondencia:}

Consuelo Meza Lagos

Miembro de la Sociedad Peruana de Estudios Léxicos (Spelex).

Correo electrónico: consuelo.meza@academiaperuanadelalengua.org 